\title{
JURISPRUDENCIA DEL TRIBUNAL CONSTITUCIONAL. EL AMPARO ELECTORAL
}

JORGE RODRIGUEZ-ZAPATA PEREZ

Profesor Titular de Derecho Constitucional

UNED 
-.. 
Revista de Derecho Político, núm. 25, 1987, págs. 199-208

\title{
JURISPRUDENCIA DEL TRIBUNAL CONSTITUCIONAL. EL AMPARO ELECTORAL
}

\author{
POR \\ JORGE RODRIGUEZ-ZAPATA PEREZ \\ Profesor Titular de Derecho Constitucional \\ UNED
}

\section{ELECCIONES GENERALES AL CONGRESO Y AL SENADO 1986}

Las últimas elecciones generales al Congreso de los Diputados y al Senado convocadas por el Real Decreto 794/1986, de 22 de abril, han servido de estreno para una nueva competencia del Tribunal Constitucional español: el amparo constitucional contra la proclamación de candidaturas y candidatos, introducido en nuestro ordenamiento por el artículo 49 de la Ley Orgánica 5/1985, de 19 de junio, del Régimen Electoral General.

\section{EL REFERIDO ARTICULO 49 DISPONE QUE:}

“1. A partir de la proclamación, cualquier candidato excluido y los representantes de las candidaturas proclamadas o cuya proclamación hubiera sido denegada disponen de un plazo de dos días para interponer recurso contra los acuerdos de proclamación de las Juntas Electorales, ante el Juzgado de lo contencioso-administrativo. En el mismo acto de interposición debe presentar las alegaciones que estime pertinentes acompañadas de los elementos de prueba oportunos.

2. El plazo para interponer el recurso previsto en el párrafo anterior discurre a partir de la publicación de los candidatos proclamados, sin perjuicio de la preceptiva notificación al representante de aquel o aquellos que hubieran sido excluidos. 
3. La resolución judicial, que habrá de dictarse en los dos días siguientes a la interposición del recurso, tiene carácter firme e inapelable, sin perjuicio del procedimiento de amparo ante el Tribunal Constitucional, a cuyo efecto, con el recurso regulado en el presente artículo, se entenderá cumplido el requisito establecido en el artículo 44.1.c) de la Ley Orgánica del Tribunal Constitucional.

4. El amparo debe solicitarse en el plazo de dos dias y el Tribunal Constitucional debe resolver sobre el mismo en los tres días siguientes.»

\section{NUEVA MODALIDAD DE AMPARO}

Esta nueva modalidad de amparo ha provocado cuatro sentencias en las elecciones generales de 1986:

a) Sentencia 69/1986, de 28 de mayo (SALA PRIMERA), Ponente Don Francisco Tomás y Valiente, Presidente del Tribunal (BOE $n .^{\circ} 144$, de 17 de junio de 1986, y Jurisprudencia Constitucional, vol. XIV, págs. 195 y ss).

b) Sentencia 71/1986, de 31 de mayo (SALA PRIMERA), Ponente Don Francisco Rubio Llorente (BOE n. ${ }^{\circ}$ 144, de 17 de junio de 1986, y Jurisprudencia Constitucional, vol. XIV, págs. 205 y ss).

c) Sentencia 73/1986, de 3 de junio (SALA PRIMERA), Ponente Don Luis Díez-Picazo y Ponce de León (BOE n. ${ }^{\circ} 144$, de 17 de junio de 1986, y Jurisprudencia Constitucional, vol. XIV, págs. 219 y ss).

d) Sentencia 74/1986, de 3 de junio (SALA PRIMERA), Ponente Don Antonio Truyol Serra (BOE n. ${ }^{\circ}$ 144, de 17 de junio de 1986, y Jurisprudencia Constitucional, vol. XIV, págs. 219 y ss).

\section{ESPECIALIDADES JURIDICO-PROCESALES DEL NUEVO PROCEDIMIENTO}

En lo que respecta a las especialidades jurídico-procesales de este nuevo procedimiento ante el Tribunal Constitucional hay que destacar la dudosa aplicabilidad al mismo de las normas de procedimiento que rigen 
para el amparo constitucional común u ordinario. La imprecisa e insuficiente regulación del amparo electoral que se contiene en el artículo 49 de la Ley Orgánica 5/1985, que he transcrito, hubo de ser ampliada y concretada por el propio Tribunal Constitucional, mediante Acuerdo del Pleno de dicho órgano de 23 de mayo de 1986 (BOE n. ${ }^{\circ} 124$, de 24 de mayo) que, por su interés, es nécesario recoger:

"En uso de las facultades que le confiere el articulo 2.2 de la Ley Orgánica $2 / 1979$, de 3 de octubre, del Tribunal Constitucional, el Pleno del mismo ha aprobado las siguientes normas:

Artículo 1. ${ }^{\circ}$ El recurso de amparo frente a los acuerdos de proclamación de candidaturas previsto en el artículo 49, apartados 3 y 4, de la Ley Orgánica 5/1985, de 19 de junio, del Régimen Electoral General, se interpondrá con los requisitos indicados en el artículo 49 de la Ley Orgánica del Tribunal Constitucional. Se acompañarán tantas copias como partes hubiera habido en el proceso anterior y una más para el Ministerio Fiscal.

El plazo para su interposición será de dos días a partir de la notificación de la resolución judicial recaída en el proceso contencioso-administrativo frente al acto de proclamación de candidatos.

Artículo 2. El recurso de amparo se entenderá admitido a trámite cuando el derecho cuyo amparo se pretenda sea el alegado como fundamento del recurso contencioso-administrativo previo a que se refiere el artículo 49,1 y 2, de la Ley Orgánica 5/1985.

Articulo 3. ${ }^{\circ}$ Presentado el recurso ante un órgano judicial radicado en la sede de la Audiencia Territorial que haya entendido del recurso contencioso-administrativo previo, aquél procederá a remitir inmediatamente al Tribunal Constitucional la demanda y documentos que la acompañen, así como una copia de los mismos.

Al mismo tiempo, comunicará a la Audiencia Territorial la formalización del recurso, para que proceda a remitir a este Tribunal, en el mismo día, las correspondientes actuaciones, asi como las seguidas ante la Junta Electoral, si obraren en su poder.

Con dicha comunicación enviará a la Audiencia el resto de las copias que se acompañen del escrito de demanda y documentos adjuntos.

Artículo 4. ${ }^{\circ} \quad$ La Audiencia remitirá las actuaciones en el día en que reciba la comunicación a que se refiere el artículo anterior, y dará simultáneamente traslado de la demanda a las partes en el procedimiento previo, con excepción de la demandante en amparo, para que en el plazo de dos dias puedan personarse, mediante Procurador habilitado, ante el Tribunal Constitucional, y formular las alegaciones que estimen convenientes a su derecho.

Articulo 5. El dia de recibimiento por parte del Tribunal Constitucional de la demanda se dará vista de la misma al Ministerio Fiscal, para que en el plazo de un día pueda efectuar las alegaciones procedentes.

Artículo 6. ${ }^{\circ}$ Deducidas las alegaciones a que se refiere el artículo anterior, o 
transcurrido el plazo previsto en el mismo, la Sala del Tribunal Constitucional dictará sentencia, sin más trámite, en el plazo de tres días.

Articulo $7^{\circ}$ La Sala, al resolver el amparo, pronunciará en su sentencia alguno de estos fallos:

a) Inadmisibilidad del recurso.

b) Estimación de la demanda y reconocimiento, en su caso, del derecho del recurrente a figurar entre los candidatos.

c) Desestimación de la demanda.

Artículo 8. ${ }^{\circ}$ De acuerdo con lo señalado en el artículo 119 de la Ley Orgánica $5 / 1985$, se entenderán naturales los dias a que se refieren los articulos anteriores.

DISPOSICION FINAL: EI presente acuerdo entrará en vigor el mismo día de su publicación en el Boletín Oficial del Estado".

La primera reflexión que suscita esta importante normativa es la de que confirma plenamente la tesis expuesta por mi hace años en esta misma Revista sobre la potestad reglamentaria del Tribunal Constitucional («La Corte Constitucional italiana: ¿Modelo o advertencia?", RDDP, 7 [1980], págs. 72 y ss.). Quienes no aceptan que la Constitución confiere a los órganos constítucionales, y en especial al Tribunal Constitucional, una potestad reglamentaria cuyo alcance desborda el ámbito puramente doméstico o de autoorganización deben, justificar cómo podria haber sido corregida la clara insuficiencia del artículo 49 de la Ley Orgánica $5 / 1985 \mathrm{sin}$ el uso de esa potestad que se les antoja exorbitante.

La labor de integración praeter legem de las lagunas de la Ley Electoral no resultó, sin embargo, suficiente en este caso. Aunque la Ley Orgánica 5/1985 no se había preocupado, al perfilar el proceso sumarísimo de amparo electoral, de declarar qué disposiciones de procedimiento ante el Tribunal Constitucional eran aplicables al nuevo proceso, la Sala I del Alto Tribunal exigió, con indudable rigor, el régimen de postulación normal previsto en el artículo 81 de la LOTC para los procesos constitucionales. Cierto es que un recurrente avisado habría podido inducir la exigencia de comparecer mediante Procurador asistido de Abogado, de lo dispuesto en el artículo $4 .^{\circ}$ del Acuerdo del Pleno del Alto Tribunal de 23 de mayo de 1986. Pero no menos cierto resulta que el referido Acuerdo entró en vigor a las 0 horas del día 24 de mayo de 1986 (día de publicación del mismo en la Gaceta), mientras que el primer amparo electoral tenía entrada en el Registro del Alto Tribunal el día 26 de mayo siguiente. Tampoco se infiere, de forma indubitada, que la postulación normal en los procesos constitucionales fuera aplicable a los recursos de amparo 
electorales ya que el Acuerdo de 23 de mayo no lo afirma expresamente $\mathrm{y}$, last but not least, la jurisdicción contencioso-administrativa había venido excusando a las partes de una postulación profesionalizada en los recursos contencioso-electorales, en razón de su carácter sumarísimo y del antiformalismo que los preside (conf. J. ROUANET MOSCARDO y J. M. ${ }^{a}$ ALVAREZ-CIENFUEGOS, El recurso contencioso-electoral, Madrid, 1983, págs. 91 y ss., con sobradas referencias jurisprudenciales).

Lo cierto es que los cuatro recursos de amparo electoral deducidos ante el Tribunal Constitucional en las elecciones generales de 1986 incurrieron en vicios de postulación, al exigir la Sala $1 .^{a}$ del Alto Tribunal la representación de Procurador del llustre Colegio de Madrid - sede del Tribunal- con poder al efecto, y la dirección de Letrado incorporado como ejerciente a cualquiera de los Colegios de España (art. 81 LOTC).

La subsanación de estos vicios de postulación no podía resultar fácil al ser claramente inaplicable a los amparos electorales el plazo de diez días, para corregir los motivos de inadmisión subsanables, que prevé el artículo 85.2 de la LOTC. El artículo $2 .^{\circ}$ del Acuerdo de 23 de mayo de 1986 parece excluir expresamente del proceso de amparo electoral el trámite de inadmisión, debiendo ser la sentencia definitiva la que se pronuncie sobre la concurrencia de los presupuestos procesales. Sin embargo, la práctica creada en los cuatro casos que se examinan consistió en otorgar un plazo de un día - no previsto en parte alguna- a las partes para la subsanación de los defectos de postulación advertidos. Veamos el razonamiento de la Sentencia 71/1986 (fundamento jurídico $1^{\circ}$ ) sobre este problema:

«Tres de los solicitantes de amparo... carecen de postulación procesal, presupuesto que sólo cubren en parte los Abogados comparecientes por los dos primeros y el que asiste al representante de la tercera, toda vez que el artículo 81.1 de la Ley Orgánica de este Tribunal exige que se complete con la representación a cargo de Procurador. En la escueta regulación que el artículo 49 de la Ley Electoral contiene de nuestro proceso de amparo no se prevé un trámite de subsanaciones dado el perentorio plazo de tres días señalado para la completa tramitación de este recurso; no obstante lo cual, se ha ofrecido a los referidos recurrentes la oportunidad de comparecer por medio de Procurador, sin que lo hayan efectuado en el plazo de un día otorgado al efecto. Ello es suficiente para una total desestimación del amparo solicitado respecto de ellos; procediendo a examinar a continuación las pretensiones de los restantes recurrentes que sí han subsanado su inicial defecto de postulación".

Dejando aparte lo opinable que es el riguroso plazo de un día concedido - debía admitirse la subsanación hasta el momento en que la Sala se reuniese para deliberación y fallo, agotando al máximo el plazo previsto en el artículo 6..$^{\circ}$ del Acuerdo de 23 de mayo de $1986-y$ la resolución de desestimar el amparo - cuando el fallo debía ser de inadmi- 
sión, a tenor del artículo $7 .^{\circ}$ del mismo Acuerdo-, parece excesivo el formalismo mostrado en estas sentencias, que contrasta con la mayor flexibilidad que ha inspirado a los Tribunales del orden contenciosoadministrativo.

Finalmente conviene destacar que todos los recursos de amparo electoral fueron encomendados -en las elecciones generales de 1986a la Sala I del Tribunal Constitucional, según un criterio de concentración que se verá confirmado si es la Sala II la que conoce los recursos que se interpongan con ocasión de las próximas elecciones autonómicas, locales y al Parlamento europeo.

\title{
5. SENTENCIAS EMITIDAS SOBRE ESTA NUEVA MODALIDAD DE AMPARO
}

Dado el brevísimo plazo concedido por la Ley Orgánica 5/1985 para la sustanciación y fallo de estos recursos, no se han producido - como era de esperar- sentencias extensas (sentencias-enciclica) en su resolución. Se resolvieron los cuatro casos presentados con sentencias escuetas que ofrecen poca doctrina general sobre esta nueva modalidad de amparo. Como excepción hay que hacer mérito de la Sentencia $71 / 1986$, que aclara que el amparo electoral no es otra cosa que un verdadero y propio recurso de amparo, con las especialidades jurídico-procesales a que obliga la concreta materia sobre la que versa. El fundamento juridico $2^{\circ}$ de la citada sentencia reza:

\begin{abstract}
“El recurso constitucional de amparo sólo cabe contra los actos del poder que violen los derechos y libertades referidos en el art. 53.2 de la Constitución (Constitución Española, art. 161 b). La Ley ha de precisar en qué casos y con arreglo a qué formas (ibid.) será posible acudir a él, pero no extenderlo a objetos y finalidades distintas de la señalada. Es por ello evidente que la Ley Orgánica 5/1985, de Régimen Electoral General, al prever una modalidad específica del recurso de amparo contra actos atinentes a la proclamación de candidaturas electorales, no ha alterado ni podia alterar la naturaleza de un recurso que, como se dice antes, no es disponible para el legislador. Desde esta perspectiva ha de juzgarse la pretensión de los demandantes de amparo en el presente caso".
\end{abstract}

Dificilmente se puede sintetizar en menos palabras cuál ha sido la voluntad del legislador orgánico al establecer el amparo electoral. Podría pensarse que, según la idea kelseniana, la Ley Orgánica 5/1985 habia decidido convertir a nuestro Tribunal Constitucional en un Tribunal electoral, según el modelo del artículo 141 de la Constitución austríaca, que atribuye al Verfassungsgerichthof plena competencia para examinar im- 
pugnaciones de la elección de Presidente federal o de las elecciones de los órganos representativos generales (Nationalrat, Bundesrat, Landtag, Gemeinderat) o sobre las pérdidas de mandato de miembros de órganos representativos. Igual competencia tiene atribuida el Tribunal Constitucional alemán (art. 41.2 de la Ley Fundamental), que admite amparos (Beschwerden) contra las decisiones del Bundestag sobre la validez de las actas y credenciales de sus miembros o contra la decisión por la que se decreta la pérdida del mandato de un diputado. Sin embargo el artículo 49 de nuestra Ley Electoral difícilmente puede ser interpretado en tal sentido. No me parece decisivo que el precepto citado utilice el nomen iuris de amparo (art. 49.4) o procedimiento de amparo (art. 49.3) para calificar el recurso que, con cierta timidez, establece. Podria argumentarse que la Ley Electoral, en cuanto ley orgánica, es competente para atribuir nuevas materias al conocimiento de nuestro Tribunal Constitucional, como expresamente reconoce el artículo 161 d) de la Constitución. El uso del nomen iuris Beschwerden no ha impedido que, en Alemania, se configuren los procesos que enjuician la validez de las elecciones como procesos objetivos en los que se garantiza el exacto cumplimiento de la legalidad electoral, más que los derechos subjetivos de los recurrentes. Pero lo cierto es que, más allá de la calificación dada por el legislador a estos amparos, difícilmente puede defenderse que "la escueta regulación" del artículo 49 de la Ley Electoral haya pretendido otorgar a nuestro Tribunal las funciones de un Tribunal electoral de corte austríaco. $Y$ ello porque, además de limitarse el recurso a quien aún es mero candidato (y no miembro de un órgano representativo), sigue vigente el principio esencial que prohíbe considerar al Tribunal en sede de amparo como una segunda instancia que pueda enjuiciar la actuación del Tribunal a quo en lo que no sea violación de derechos fundamentales o libertades públicas:

"Cuando la Sala conozca del recurso de amparo respecto de decisiones de los Jueces y Tribunales limitará su función a concretar si se han violado derechos o libertades del demandante y a preservar o restablecer estos derechos o libertades y se abstendrá de cualquier otra consideración sobre la actuación de los órganos jurisdiccionales" (art. 54 LOTC).

Parece, por tanto, magistral la configuración que la Sentencia 71/1986 da al nuevo procedimiento de amparo previsto en la Ley Electoral.

El recurso de amparo electoral tiene, por tanto, idéntica extensión y límites que el recurso de amparo constitucional.

Finalmente, por su importancia, conviene hacer mérito en esta crónica de la Sentencia 73/1986; la única que, con razonamiento impecable, anula la sentencia pronunciada en via contenciosa y restablece al re- 
currente en su derecho a ser proclamado candidato a las elecciones generales. La sentencia, en definitiva, restablece el exacto cumplimiento de la legalidad electoral, ya que una inexacta observancia de la misma había vulnerado el derecho de sufragio pasivo del recurrente. 